\title{
Е.А. Барышева
}

\section{Роль публичных библиотек ЮАР в сохранении и популяризации нематериального этнокультурного наследия}

Реферат. В статье рассказывается о программе «Улвази» («Знание»), ставшей первым библиотечным проектом в ЮАР, направленным на собирание и документирование нематериального культурного наследия и осуществленным благодаря координационной деятельности Центральной библиотеки муниципального округа Этеквини (Дурбан) при активном участии общин коренного населения. Раскрывается основное содержание проекта, среди главных целей которого - коллективная подготовка базы данных онлайн по традиционной культуре зулусов (на английском и зулусском языках) как части информационно-электронных ресурсов публичных библиотек округа и повышение цифровой грамотности местных жителей. Характеризуются библиотечная сеть Этеквини, основные направления деятельности публичных библиотек в рамках реализации проекта и трудности, с которыми им пришлось столкнуться, а также структура веб-сайта «Улвази», разработанного на базе технологии web 2.0, позволяющей вовлекать большое число пользователей в создание и размещение контента. Особое внимание уделяется социальной значимости проекта, способствующего сохранению и популяризации традиционной культуры зулусов, преодолению информационного неравенства и построению толерантного общества.

Ключевые слова: нематериальное культурное наследие, традиционная культура, ЮАР, Дурбан, муниципальные библиотеки, цифровая неграмотность, база данных онлайн, цифровая библиотека традиционных знаний, вики-проект.

Для цитирования: Барышева Е.А. Роль публичных библиотек ЮАР в сохранении и популяризации нематериального этнокультурного наследия // Библиотековедение. 2017. Т. 66, № 1. С. 70-76.

$\mathrm{B}$ условиях глобализации, усиления миграционных процессов и стремительной урбанизации все отчетливее проявляется тенденция унификации и ослабления потенциала традиционных этнических культур, что приводит к постепенному исчезновению накопленных в их рамках знаний, исторического и духовного опыта. В ЮАР, одной из наиболее многонациональных стран региона, вопросами поддержки и развития культур коренных народов начали заниматься совсем недавно - после отмены режима апартеида в 1994 году. Важной вехой на этом пути стала разработка Министерством науки и технологий основ государственной политики в области сохранения и популяризации нематериального этнокультурного наследия. В 2006 г. министерство подготовило итоговый документ, отдельный параграф которого посвящен деятельности библиотек: данные учреждения призваны собирать и хранить свидетельства истории и традиционных культур коренных народов, разрабатывать новые способы и формы доступа к культурному наследию, способствовать популяризации традиционных знаний и практик. Биб-

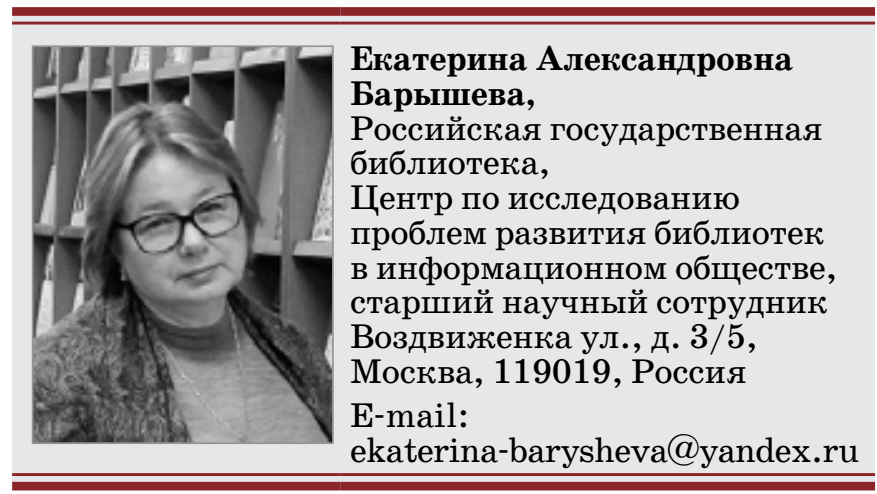

лиотеки в соответствии со своими социальными функциями должны тесно взаимодействовать с общинами коренного населения, создавать возможности для изучения местных языков, истории и культуры, содействовать росту информационной и цифровой грамотности в интересах устойчивого развития [1, p. 29].

Программа «Улвази» ( ЗЗнание» на языке зулу) стала первым библиотечным проектом в ЮАР, направленным на осуществление подобных задач. Проект был начат в 2008 г. по инициа- 
тиве ведущего специалиста в области развития и поддержки информационных технологий Центральной библиотеки муниципального округа Этеквини (Дурбан) Э. Грейлинг. По ее словам, идея «Улвази» возникла после долгих размышлений о том, как можно привлечь молодых людей в библиотеки. Не вызывало сомнений, что необходим прорывной проект с понятными целями и интересным содержанием, ориентированный на запросы местного населения и предполагающий использование популярных в современной молодежной среде средств коммуникации - Интернета и сотовой связи [2, р. 56].

В результате было решено объединить усилия всех общедоступных, финансируемых муниципалитетом библиотек округа для реализации вики-проекта библиотеки традиционных знаний зулусов - коренного населения провинции Квазулу-Натал. Главными «поставщиками» информации, авторами материалов, должны были стать сами жители расположенных в Дурбане и его окрестностях зулусских общин, которые благодаря библиотекам получили возможность принять непосредственное участие в изучении и популяризации своей традиционной культуры и истории.

Проект преследовал еще одну, не менее важную и амбициозную цель - преодолеть цифровую неграмотность значительной части коренного населения округа и помочь зулусам ощутить свою принадлежность к глобальному информационному обществу [3, p. 31]. Программа, предложенная Центральной библиотекой, была одобрена муниципалитетом Этеквини, который с 2010 г. начал ее ежегодное финансирование. Значительную финансовую поддержку «Улвази» оказал Институт им. Гёте, признав проект способствующим развитию онлайн-ресурсов по языкам и традиционным культурам коренных народов и служащим интересам местных жителей [4, р. 7]. В 2012 г. программа заняла второе место в номинации «Приобщение населения к информационным технологиям» на ежегодной конференции «Highway Africa», организуемой одним из ведущих высших учебных заведений ЮАР - Университетом Родса в Грейамстауне [5].

В 2016 г. программе «Улвази» исполнилось семь лет, и ее разработчики решили подвести некоторые итоги. «Сейчас именно то время, когда следует оглянуться назад и вспомнить, с чего мы начинали, каковы были наши цели, и как мы прошли этот путь $<. .>$, чтобы понять, где мы находимся, как далеко и в каком направлении нам следует двигаться дальше (перевод наш. $E$. Б.)», - написал в своем блоге Н. Макналти, один из «родоначальников» и лидеров проекта [6]. Представляется, что опыт, накопленный южноафриканскими специалистами, будет интересен для отечественных библиотек, в последнее десятилетие активно позиционирующих краеведение и повышение информационной грамот- ности населения как ведущие направления своей деятельности.

\section{Почему именно традиционные знания и культура зулусов?}

Первый вопрос, на который предстояло ответить инициаторам «Улвази», - какая тела проекта поможет библиотекам наиболее полно реализовать свои социальные функции? Для того, чтобы понять причину выбора, следует сказать несколько слов о самом округе Этеквини и его истории. Муниципальный округ Этеквини (в переводе с языка зулу «залив») расположен на восточном побережье ЮАР, в провинции Квазулу-Натал ${ }^{1}$. Он был образован в 2000 г. и представляет собой агломерацию, сложившуюся вокруг города Дурбана. По количеству населения (более 3 млн 442 тыс. человек) округ занимает третье место после Йоханнесбурга и Кейптауна [7]. Этеквини - один из самых молодых регионов страны: более 95\% его жителей не достигли 64 лет. По расовому составу чернокожие африканцы составляют $73,8 \%$, белые - 6,6\%. Весьма значительна доля выходцев из Индии и других стран Южной Азии - 16,7\% . Доминирующий язык - зулу (его назвали родным более $62 \%$ жителей), на втором месте - английский $(26,5 \%)$ [7].

Административный центр округа Этеквини Дурбан - является крупным портом на африканском побережье Индийского океана. Он был основан английскими колонистами в 1835 г. и получил свое название в честь британского дипломата и военачальника, генерал-губернатора Капской колонии Бенджамена Д'Урбана. В Дурбане проживают 595 тыс. человек, из которых $51,1 \%$ чернокожих, $15,3 \%$ белых и $24,3 \%$ представителей индо-пакистанской общины, крупнейшей за пределами Индостана [7].

Коренным населением округа Этеквини, как и всей провинции Квазулу-Натал, являются зулусы. K началу XIX в. им удалось создать мощный военно-политический союз, особенно укрепившийся в период правления инкоси Чаки ${ }^{2}(1816-1828)$. Зулусское королевство, или государственное объединение Квазулу, сыграло важную роль в истории Южной Африки, став символом свободолюбия и борьбы африканского народа против колонизаторов. Более полувека на этих землях не прекращались кровопролитные столкновения. Потерпев окончательное поражение в англо-зулусской войне 1879 г., зулусы лишились своих земель и впоследствии были изгнаны в резервации.

Практика расовой сегрегации обусловила создание в Дурбане специальных кварталов для проживания этнических общин. В 1923 г. все чернокожие африканцы были выселены за пределы города в так называемые «черные поселения» (тауншипы). С 1948 г. после прихода к власти Национальной партии и официального провозглашения 
политики апартеида за пределы Дурбана было выдворено все остальное «не белое» население. Люди с черным цветом кожи могли появляться в городе только в рабочее время с письменным разрешением работодателя [8, p. 12].

Падение режима апартеида в 1994 г. привело к кардинальным изменениям в жизни Дурбана. Отток «белых» и многократное увеличение численности малограмотного и низкоквалифицированного чернокожего населения, переехавшего в город в поисках лучшей доли, породили массу проблем, в первую очередь, высокий уровень безработицы, особенно среди молодежи (39\%), и преступности [7]. Нерешенность социальных вопросов неоднократно приводила к массовым беспорядкам, в том числе, на межэтнической почве. Следует учитывать и то, что длительная политика сегрегации способствовала формированию у чернокожих граждан особого самосознания, основанного на чувстве ущемленного достоинства - чувстве, побуждающем к самым радикальным формам выражения протеста. Стремясь преодолеть негативные последствия апартеида, муниципальные власти Дурбана утвердили ряд социальных программ, в частности, направленных на реализацию прав коренного населения на сохранение и развитие традиционной культуры.

В музеях, архивах и библиотеках Дурбана хранится немало уникальных коллекций, связанных с местной историей. Однако изучение и документирование нематериального культурного наследия зулусов по понятным причинам практически не велось. Именно эти пробелы и призван восполнить проект «Улвази», направленный на собирание и документирование личных и семейных историй, традиционных знаний и практик, информации об обычаях и обрядах жизненного цикла, правилах поведения, приметах, исполнительских искусствах, праздниках, пословицах и поговорках и пр. Социальное назначение проекта не вызывает сомнений: он не только способствует формированию у оторванной от своих корней зулусской молодежи позитивной этнической идентичности, но и позволяет приобщить все многонациональное население округа к самобытному культурному наследию зулусов, способствуя восстановлению исторической справедливости и построению толерантного общества [2, p. 58].

\section{Почему именно библиотеки?}

На небольшой территории округа (2291 кв. км) функционирует разветвленная сеть общедоступных библиотек. Центральная библиотека имеет 92 библиотеки-филиала, расположенных как в самом Дурбане, так и в прилегающих к нему поселках, сельских районах и на племенных землях [9]. Часть средств на финансирование данных учреждений выделяется правительством провинции (через Департамент по делам искусств и культуры), однако основное бремя расходов ложится на муниципальный бюджет [10]. На одну библиотеку в округе приходится приблизительно 37,4 тыс. жителей (средний показатель по ЮАР - 31,6 тыс.) [11, р. 27]. Справиться с нехваткой библиотечных учреждений в труднодоступной местности помогают передвижные библиотеки. До 2020 г. муниципалитет Этеквини запланировал строительство еще трех библиотек [9].

Возглавляет библиотечную сеть округа Центральная библиотека, расположенная в старой части Дурбана. Ее история началась с открытия в 1853 г. Института механики. Созданная при нем для интеллектуального развития студентов и всех горожан библиотека насчитывала всего 400 книг, но уже к 1857 г. ее фонды настолько разрослись, что встал вопрос о необходимости дополнительных помещений. В 1860 г. Институт был переименован в Публичную библиотеку Дурбана. С этого времени ее посещение стало свободным и бесплатным для всех постоянных жителей города [12]. В 1911 г. библиотека получила новый статус, став Муниципальной, а с 2000 г. она известна как Центральная библиотека муниципального округа Этеквини. С 1910 г. библиотека располагается в здании городской ратуши, соседствуя с приемной мэра, музеем естественной истории, художественной галереей и концертным залом [8, p. 11]. В настоящее время фонды библиотеки насчитывают более 1 млн экз., число пользователей превышает 593 тыс. человек [13]. В 2014 г. власти Этеквини объявили о завершении работы над проектом нового современного комплекса Центральной библиотеки, под строительство которого уже выделен участок площадью 15 тыс. кв. м в деловом районе города [10].

В соответствии с принципиальным положением библиотечной политики провинции Квазулу-Натал, читальные залы всех муниципальных библиотек округа открыты для свободного посещения всеми желающими, вне зависимости от того, записан человек в библиотеку или нет. Доступ к компьютерам, Интернету и электронной почте предоставляется бесплатно [11, p. 30]. Единственное ограничение касается детей - они могут пользоваться Интернетом только с письменного разрешения родителей [14]. Запись в библиотеку является необходимым условием лишь для пользования абонементом ${ }^{3}$.

В последние годы в округе многое сделано для создания единого информационно-библиотечного пространства: работают сводные электронные каталоги библиотек Этеквини и провинции Квазулу-Натал, полнотекстовые базы данных ряда периодических национальных и зарубежных изданий, доступ к которым осуществляется, в том числе, с официального веб-сайта муниципального округа Этеквини [13].

Библиотеки, расположенные за пределами городской черты в тауншипах, сельских районах и на племенных землях, как правило, являются единственными центрами культуры, к тому же предлагающими свободный доступ к Интернету. Важность последнего трудно переоценить: у $85 \%$ сельских 
жителей округа нет доступа к Сети, домашний Интернет есть лишь у $5 \%$ [7]. Библиотечные сотрудники пользуются доверием и уважением местных жителей и лидеров общин, они знают их проблемы и понимают, как надо работать с данной аудиторией.

Наличие разветвленной сети, свободный доступ в читальные залы, бесплатный Интернет, квалифицированные, отзывчивые и бескорыстные сотрудники - вот причины, по которым организаторы «Улвази» сделали библиотеки ключевым звеном реализации своего проекта.

\section{Технологическое оснащение проекта. Почемy web 2.0?}

Уже на начальной стадии подготовки проекта его авторы приняли принципиальное решение - везде, где только возможно, применять программное обеспечение с открытым исходным кодом. Использование технологии web 2.0 позволяет привлечь к участию в проекте большое количество людей, принадлежащих к различным культурным сообществам, и создать контент на нескольких языках (английский, зулу и его локальные диалекты). В результате проект становится удобной цифровой платформой для кросскультурных коммуникаций $[2$, p. 56].

Веб-сайт «Улвази» («Цифровая общественная библиотека традиционных знаний зулусов округа Этеквини»), работающий на технологии вики, открыт для чтения и позволяет пользователям получить быстрый доступ к любому компоненту проекта. На сайте содержится информация о самой программе, ее целях и задачах, необходимые контактные сведения. Основные разделы сайта («культура», «история», «люди», «места») состоят из отдельных статей и наполняются самими пользователями. Стать автором материала и полноправным участником «Улвази» может каждый: для публикации необходимо создать учетную запись или авторизоваться через уже имеющийся аккаунт в Facebook или Google/Gmail. Для новичков размещена пошаговая инструкция. Приветствуется публикация фотографий, аудиозаписей и видеоматериалов. Содержание статей обязательно должно соответствовать тематике и географии проекта, в противном случае материал будет заблокирован администратором. Статьи, как правило, публикуются на двух языках - английском и зулу; в случае отсутствия полного перевода обязательно дается аннотация.

В настоящее время на сайте можно прочитать более 800 статей, созданных пользователями, из которых более половины написаны на зулу [15]. Материал структурируется по четырем большим категориям, которые, в свою очередь, делятся на подкатегории, добавляемые в зависимости от содержания статей. По количеству страниц наиболее популярными являются категории «люди» и «культура», подкатегории: «личные истории», «детские истории и легенды», «традиционные игры», «родовые предания», «история фамилий», «традиционные церемонии». Среди самых посещаемых статей - материалы о традиционной зулусской свадьбе, обрядах инициации, целительстве, природных приметах, зулусской одежде, рецептах приготовления традиционных паровых лепешек и пива. Важно подчеркнуть, что при публикации материалов особое внимание уделяется соблюдению права интеллектуальной собственности на традиционные знания и традиционные выражения культуры/фольклора [16].

Интересным разделом сайта «Улвази» являются «Новости»: в них регулярно появляются сообщения о повседневной жизни зулусов, изучении их языка, истории и культуры, а также о значимых культурных мероприятиях, научных конференциях, книжных новинках, музейных коллекциях и пр.

Внутренние ссылки на сайте упрощают поиск и переходы между взаимосвязанными фрагментами информации, а внешние - ведут на веб-сайты ряда музеев Дурбана, официальный веб-сайт муниципального округа Этеквини и др. Для упрощения навигации используется поиск по тегам. Для расширения коммуникации проект представлен в социальных сетях Facebook, Twitter и Google+ [5].

Создано специальное приложение для использования программы на мобильных устройствах, за которым, по мнению авторов проекта, - будущее «Улвази». Компьютеры для большинства сельских африканских семей - непозволительная роскошь, поэтому ознакомление с контентом сайта, а также ввод информации происходят в близлежащих библиотеках и школах. Мобильными же телефонами пользуются 90,7\% жителей округа [7]. Использование мобильного приложения позволяет не только значительно расширить круг участников проекта, но и удешевить его для библиотек, существенно снизив затраты на электроэнергию [2, p. 58].

\section{Библиотека как центр изучения культуры и обучения местного сообщества}

Итак, какие же функции выполняют библиотеки в рамках «Улвази»? Во-первых, они проводят работу по популяризации программы среди населения, занимаются организацией презентаций, размещают рекламные материалы. Важными являются встречи с представителями локальных властей и традиционными лидерами (вождями) для получения формального разрешения на сбор информации и привлечения волонтеров к сотрудничеству [3, p. 33].

Во-вторых, библиотеки занимаются обучением местных жителей, пожелавших присоединиться к проекту. Участие в программе абсолютно добровольно, информатором может стать каждый человек, независимо от возраста, социального по- 
ложения и образования. Как правило, волонтерами оказываются молодые люди, часто безработные, которые интересуются историей и культурой своего народа, а также рассчитывают освоить новые навыки и получить интересный опыт полевой работы. Библиотекари объясняют им основы успешного интервьюирования, методику сбора устного и визуального материала, ведения и обработки записей, учат пользоваться фото- и видеоаппаратурой, помогают с выбором целевой аудитории (старейшины, мастера традиционных ремесел, исполнители и пр.). В среднем волонтеры делают по два-три материала в месяц и раз в месяц собираются в библиотеке для обсуждения возникающих проблем. Библиотекари также занимаются сбором информации, практикуется проведение встреч с интересными людьми, мастер-классов народных умельцев, конкурсов сказителей и пр. [3, p. 34].

Как уже отмечалось, одна из главных целей проекта - приобщение представителей коренного населения округа к современным информационным технологиям. В библиотеках регулярно проводятся занятия по цифровой грамотности, где желающих обучают пользоваться Интернетом, помогают добавлять информацию на сайт «Улвази». За время реализации проекта библиотеки в порядке эксперимента подготовили более 20 специалистов - администраторов сайтов и помогли им в дальнейшем трудоустройстве. Особое внимание обращается на сотрудничество с сельскими школами и подготовку информаторов среди их учеников [2, р. 56].

Координацию осуществляют сотрудники Центральной библиотеки округа в Дурбане. Они оказывают коллегам «из глубинки» методическую и технологическую поддержку, регулярно проводят обучающие семинары, занимаются структурированием и редактированием статей, переводами на английский/зулусский языки, транскрибацией аудиозаписей в текст и обеспечивают хранение собранных документальных материалов [16].

К сожалению, за истекший период организаторам проекта удалось выполнить далеко не все из задуманного. Среди главных препятствий - нехватка библиотечных учреждений и их неравномерное распределение по районам, а также отсутствие библиотечных пунктов на труднодоступных племенных территориях. Проблему могли бы решить библиотеки-контейнеры (на базе морских грузовых контейнеров), но на это необходимы дополнительные средства [16]. В последнее время большие надежды возлагаются на сотрудничество с местными музеями истории, которые все чаще становятся полноправными участниками проекта [5] .

Непредвиденной оказалась проблема текучести кадров. Как правило, волонтеры из местных жителей быстро покидали проект, если находили другую, оплачиваемую, работу. Не было учтено и то, что далеко не все волонтеры готовы нести транспортные расходы. Авторы проекта считают, что улучшить положение могли бы небольшие стипендии, поощрительные грамоты и вознаграждения, повышающие престиж волонтерского труда [16].

Осложнила осуществление проекта и нехватка персонала для обучения компьютерной грамотности. Занятия с большими группами оказались неэффективными из-за недостатка компьютеров, а на малые группы или индивидуальные занятия не хватало ни сотрудников, ни времени. Загруженность библиотекарей приводила к тому, что они не успевали выполнять свои непосредственные обязанности. Затрудняла работу и недостаточная языковая квалификация библиотечных работников, что мешало быстро и качественно вводить и систематизировать информацию и на английском, и на зулу [3, p. 37].

Несмотря на определенные неудачи и разочарования, авторы проекта достигли существенных успехов. За семь лет сайт «Улвази» посетили пользователи из 182 стран, включая Австралию, Великобританию, Германию, Канаду, США и Францию. Однако больше всего посещений $(60 \%)$ приходится на жителей ЮАР, главным образом, из КвазулуНатала и Гаутенга - провинций с самым большим зулусским населением [2, р. 58]. В настоящее время у проекта «Улвази» появилось много последователей в других районах ЮАР. Сотрудники музеев, библиотек, различных фондов, учебных заведений и научных организаций активно используют и развивают опыт дурбанских специалистов, стремясь не повторять их ошибок. Организаторы «Улвази» твердо намерены двигаться дальше, ибо, как гласит пословица зулу, «туловище слона никогда не бывает слишком тяжелым для слона» .

\section{Примечания}

1 Провинция Квазулу-Натал была образована в 1994 г. путем объединения провинции Натал и бывшего бантустана Квазулу. Общая площадь более 94 тыс. кв. км (7,7\% всей территории ЮАР). Население около 10 млн 270 тыс. человек. Административный центр - город Питермарицбург.

2 Правитель (инкоси) зулусов Чака является одним из национальных героев ЮАР. Ежегодно в конце сентября зулусы отмечают День короля Чаки (Umkhosi WeLembe) как напоминание об образовании государства Квазулу. 26 сентября 2016 г. в Дурбане на стадионе Мозес Мабида прошли грандиозные торжества в честь 200-летия государства зулусов, собравшие более 40 тыс. человек. Имя Чаки носит международный аэропорт Дурбана.

3 По правилам библиотек округа любой человек, проживающий, работающий или обучающийся на его территории, может получить индивидуальный или ученический читательский билет, дающий право на бесплатное абонементное обслуживание. Взрослый читательский билет выдается по достижении 18 лет; детский - с 12 лет (при поручительстве родителей). 


\section{Cписок источников}

1. Republic of South Africa: Indigenous Knowledge Systems Policy [Электронный pecypc]. URL: http:// www.wipo.int/edocs/mdocs/tk/en/wipo_grtkf_ ic_9/wipo_grtkf_ic_9_11.pdf (дата обращения: 15.10.2016).

2. McNulty N. Ulwazi Program: a Model for Public Participation through Digital Technology \& CrossCultural Exchange [Электронный pecypc]. URL: http://publicdiplomacymagazine.com/wp-content/ uploads/2016/03/MPD-Mag-Winter-2016-Officialpdf (дата обращения: 22.09.2016).

3. Greyling E., Zulu S. Content Development in an Indigenous Digital Library: a Case Study in Community Participation [Электронный pecypc]. URL: http:// www.ifla.org/files/assets/hq/publications/ifla-journal/ifla-journal-36-1_2010.pdf (дата обращения: 09.09.2016).

4. Liebetrau P. Preserving our Heritage. An Independent Advantage [Электронный pecypc]. URL: http://www. unesco.org/new/fileadmin/MULTIMEDIA/HQ/CI/ CI/pdf/mow/VC_Liebetrau_27_B_1430.pdf (дата обращения: 10.09.2016).

5. Ulwazi: About [Электронный pecypc]. URL: http:// ulwaziprogramme.org/about (дата обращения: 14.08.2016).

6. Where We've Come From, Where We're Going To [Электронный ресурc]. URL: http://www.ulwaziprogramme.org/2016/06/where-weve-come-from-wherewere-going-to/ (дата обращения: 09.09.2016).

7. Statistics South Africa. Ethekwiny Municipality [Электронный ресурc]. URL: http://www.statssa. gov.za/?page_id=1021\&id=ethekwini-municipality (дата обращения: 10.10.2016).

8. Durban. A Return to Paradise and its People [Электронный pecypc]. URL: http://www.durban. gov.za/Discover_Durban/Documents/Durban \% 20 Book\% 2020111.pdf (дата обращения: 08.09.2016).
9. eThekwini Boosts Financial Support for KZN's Arts Scene (16.03.2016) [Электронный ресурс]. URL: http://www.news24.com/SouthAfrica/News/ ethekwini-boosts-financial-support-for-kzns-artsscene-20160315 (дата обращения: 13.10.2016).

10. eThekwini Municipality Invests Millions in Construction of Library (20 august 2014) [Электронный pecypc]. URL: http://www.sabc.co.za/news/ a/85760a80452a8023bf6cbfa5ad025b24/EThekwinimunicipality-invests-miillions-in-construction-oflibrary-20140820 (дата обращения: 13.10.2016).

11. The State of Libraries in South Africa (August 2015) [Электронный ресурc]. URL: http://www.liasa-new. org.za/wp-content/uploads/2015/09/State-of-SAlibraries-2015.pdf (дата обращения: 08.08.2016).

12. South Africa History Online [Электронный pecypc]. URL: http://www.sahistory.org.za/market-square (дата обращения: 10.10.2016).

13. Libraries. "Entice, Excite, Educate and Embrace" [Электронный ресурc]. URL: http://www.durban. gov.za/City_Services/ParksRecreation/libraries/ Pages/default.aspx (дата обращения: 20.09.2016).

14. Internet Access Policy and Email Code of Practice [Электронный pecypc]. URL: http://www.durban. gov.za/City_Services/ParksRecreation/libraries/ Policies_Tariffs/Pages/Internet-Access-Policyand-email-Code-of-Practice.aspx (дата обращения: 20.09.2016).

15. Ulwazi: Bigger than Wikipedia! [Электронный pecypc]. URL: http://www.ulwaziprogramme. org/2016/08/ulwazi-bigger-than-wikipedia/ (дата обращения: 10.09.2016).

16. Greyling E., McNulty N. How to Build an Indigenous Digital Library through Community Participation: the Case of Ulwazi Programme [Электронный pecypc]. URL: http://www.mcnulty.co.za/wpcontent/uploads/2014/05/SCECSAL_2012_ GreylingMcNulty_APA-libre.pdf (дата обращения: 14.08.2016).

\title{
The Role of Public Libraries in the Republic of South Africa in Safeguarding and Promotion of the Intangible Cultural Heritage
}

\author{
Ekaterina A. Barysheva, \\ The Russian State Library, 3/5 Vozdvizhenka Str., Moscow, 119019, Russia \\ E-mail: ekaterina-barysheva@yandex.ru
}

\begin{abstract}
The article discusses the "Ulwazi" ("Knowledge") Program, which became the first library project in South Africa, aimed at collecting and documenting of the intangible cultural heritage and being realized thanks to the coordinating activities of the Central library of the municipality of eThekwini (Durban) and the active participation of indigenous communities. The author reveals the concept of the project; among its core objectives are the creation of a collaborative online database on the traditional Zulu culture (in both English and Zulu) as part of the information and digital resources of the public libraries of the district, and the growth of digital literacy skills of the local population. The article describes the library network of eThekwini, the main activities of public libraries in the framework of the project implementation, and the
\end{abstract}


difficulties they had to face, as well as the structure of the "Ulwazi" web site, developed on the basis of Web 2.0 technology that allows to involve a large number of users in the creation and distribution of content. Special attention is paid to the social importance of the project contributing to the preservation and promotion of traditional Zulu culture, bridging the digital divide and building a tolerant society.

Key words: Intangible Cultural Heritage, Traditional Culture, Republic of South Africa, Durban, Municipal Libraries, Digital Illiteracy, Online Database, Digital Library of Traditional Knowledge, Wiki-Project.

Citation: Barysheva E.A. The Role of Public Libraries in the Republic of South Africa in Safeguarding and Promotion of the Intangible Cultural Heritage, Bibliotekovedenie [Library and Information Science], 2017, vol. 66, no. 1, pp. 70-76.

\section{References}

1. Republic of South Africa: Indigenous Knowledge Systems Policy. Available at: http://www.wipo.int/ edocs/mdocs/tk/en/wipo_grtkf_ic_9/wipo_grtkf_ ic_9_11.pdf (accessed 15.10.2016).

2. McNulty N. Ulwazi Program: a Model for Public Participation through Digital Technology \& Cross-Cultural Exchange. Available at: http://publicdiplomacymagazine.com/ wp-content/uploads/2016/03/MPD-Mag-Winter2016-Official-.pdf (accessed 22.09.2016).

3. Greyling E., Zulu S. Content Development in an Indigenous Digital Library: A Case Study in Community Participation. Available at: http://www.ifla.org/files/ assets/hq/publications/ifla-journal/ifla-journal36-1_2010.pdf (accessed 09.09.2016).

4. Liebetrau P. Preserving our Heritage. An Independent Advantage. Available at: http://www.unesco.org/ new/fileadmin/MULTIMEDIA/HQ/CI/CI/pdf/mow/ VC_Liebetrau_27_B_1430.pdf(accessed 10.09.2016).

5. Ulwazi:About. Available at: http://ulwaziprogramme. org/about (accessed 14.08.2016).

6. Where We've Come From, Where We're Going To. Available at: http://www.ulwaziprogramme. org /2016/06/where-weve-come-from-where-weregoing-to/ (accessed 09.09.2016).

7. Statistics South Africa. Ethekwiny Municipality. Available at: http://www.statssa.gov.za/?page $i d=1021 \& i d=$ ethekwini-municipality (accesse $\bar{d}$ 10.10.2016).

8. Durban.A Return to Paradise and its People. Available at: http://www.durban.gov.za/Discover_Durban/ Documents/Durban\% 20Book\% 2020111.pdf (accessed 08.09.2016).

9. eThekwini Boosts Financial Support for KZN's Arts Scene (16.03.2016). Available at: http://www. news24.com/SouthAfrica/News/ethekwini-boosts- financial-support-for-kzns-arts-scene-20160315 (accessed 13.10.2016).

10. eThekwini Municipality Invests Millions in Construction of Library (20 august 2014). Available at: http://www.sabc.co.za/news/ a/85760a80452a8023bf6cbfa5ad025b24/EThekwinimunicipality-invests-miillions-in-construction-of-library-20140820 (accessed 13.10.2016).

11. The State of Libraries in South Africa (August 2015 ). Available at: http://www.liasa-new.org.za/wpcontent/uploads/2015/09/State-of-SA-libraries2015.pdf (accessed 08.08.2016).

12. South Africa History Online. Available at: http:// www.sahistory.org.za/market-square (accessed 10.10.2016).

13. Libraries. "Entice, Excite, Educate and Embrace". Available at: http://www.durban.gov.za/City_ Services/ParksRecreation/libraries/Pages/default. aspx (accessed 20.09.2016).

14. Internet Access Policy and Email Code of Practice. Available at: http://www.durban.gov.za/City_ Services/ParksRecreation/libraries/Policies_ Tariffs/Pages/Internet-Access-Policy-and-emailCode-of-Practice.aspx (accessed 20.09.2016).

15. Ulwazi: Bigger than Wikipedia! Available at: http:// www.ulwaziprogramme.org/2016/08/ulwazi-biggerthan-wikipedia/ (accessed 10.09.2016).

16. Greyling E., McNulty N. How to Build an Indigenous Digital Library through Community Participation: the Case of Ulwazi Programme. Available at: http:// www.mcnulty.co.za/wp-content/uploads/2014/05/ SCECSAL_2012_GreylingMcNulty_APA-libre.pdf (accessed 14.08.2016). 